\title{
The Influence of some Prefermentative Treatments on Compositional and Organoleptic Features of Fetească Albă Wines
}

\author{
Ana- Maria MOROŞANU ${ }^{1 *}$, Cintia COLIBABA ${ }^{1}$, Marius NICULAUA ${ }^{2}$, Bogdan C-tin NECHITA ${ }^{1}$, Cătălin \\ ZAMFIR $^{1}$,Valeriu V. COTEA ${ }^{1}$, Alexandru Cătălin TARȚIAN ${ }^{1}$ \\ ${ }^{1}$ Faculty of Horticulture, University of Agricultural Studies and Veterinary Medicine Iasi, 700490, Iasi, \\ Romania \\ ${ }^{2}$ Oenological Research Center- Romanian Academy- Iasi Branch, 700505, Iasi, Romania \\ *)Corresponding author, e-mail: morosanu.anamaria88@yahoo.ro
}

BulletinUASVM Horticulture 73(1) / 2016

Print ISSN 1843-5254, Electronic ISSN 1843-5394

DOI:10.15835/buasvmcn-hort:11398

\begin{abstract}
Wine is a product resulting from the crossing of the conditions offered by plantation and the different treatments applied by winemakers in the wine making process. The present study has evaluated the influence of pre- fermentative treatments on the physico- chemical and chromatic features of the analyzed wines, and it was also observed the differences on the sensory level. Six experimental samples were obtained: FA V0-control sample (no pre- fermentative treatments), FA V1 (pectinase and $\beta$ - glucosidase treatment), FA V2 (bentonite treatment), FA V3 (glutathione treatment), FA V4 (tannin treatment), FA V5 (gelatin and tannin treatment). The physico-chemical analyses were done according to the Compendium of International Methods of Analysis of Wine and Musts. A Shimadzu UV-1800 spectrophotometer was used to examine chromatic features, the total polyphenols index and the Folin- Ciocâlteu index. The sensory evaluation was conducted according to the evaluation method originally proposed by the International Union of Oenologists (UIO). As expected, the pre-fermentative treatments didn't have significant influence on the physico-chemical features of the wines, but important differences were identified on the sensory level and concerning the polyphenol indices.
\end{abstract}

Keywords: Fetească albă, organoleptic, prefermentative treatments, physico-chemical parameters

\section{INTRODUCTION}

In modern wine-making, besides the grape processing technology, the treatments applied to the must before fermentation also have an important role in deciding the wine's quality (Ribéreau- Gayon et al., 2006a).

Applying pre-fermentative treatments on wines at the right time and in the right doses, increases the probability of obtaining a higher quality product. Several studies have been performed on the effect of oenological practices on the wine's composition (Losada et al., 2011; Puig- Deu et al., 1996).

Commercially available enzymes are widely used in the oenological industry in wineproducing countries mostly to improve important characteristics of wines, such as aroma and color. Enzymes are also used to increase the grape must yield during pressing, facilitate the settling of musts and improve clarification and filtration (Salinas et al., 2003).

Bentonite is a technological aid widely used in winemaking to remove or reduce the concentration of undesirable constituents. In particular, it acts as a settling aid to remove proteins, thus reducing the risk of protein haze in wine, whose occurrence could compromise its acceptance by the consumer.

In what concerns glutathione treatment, in the past it has received important attention due to its important role during the oxidation of white must to form the grape reaction product (GRP), which prevents browning to a certain extent. 
Exogenous tannins are frequently added to wines during the winemaking process in order to stabilize color, to modify mouth-feel, to mask green characters, to increase polyphenolics and aromatic stability (Harbertson et al., 2011; Parker et al., 2007).

Gelatin it's primarily used to soften wines but it can also be used to reduce the phenol level and brown color in white juice before fermentation. Therefore, the addition of gelatin in the must before fermentation process, ensures a certain level of clarity on the environment treated, improve sensory quality and leads on the obtaining of balanced wines.

The main objective of the present study is to evaluate the influence of some pre- fermentative treatments on the physico-chemical and chromatic features on the analyzed wines, and to observe differences on the sensory level.

\section{MATERIALS AND METHODS}

Reagents for pre-fermentative treatments: In what concerns the enzymatic treatments, there were used enzymes from the Zymoclaire range produced by Sodinal Company, for the bentonite sample it was used Bentonite Clarit 360, for tannin sample Taniblanc and for gelatin treatment Gelclar.

Reagents for polyphenolic compounds determination: For the determination of polyphenolic compounds it was used: FolinCiocâlteu reagent and sodium carbonate 20\% concentration.

Grape samples and winemaking: In order to conduct the experiment, it was choosed a neutral grape variety: Fetească albă. The grapes were harvested in 2014 at full maturity and presented an optimal composition for obtaining dry quality wines. The grapes were crushed, destemmed and the obtained must was divided for the experimental samples.

Before starting fermentation, five oenological products were used to obtain the experimental samples: FA V0- control sample (no prefermentative treatments), FA V1 (pectinase and $\beta$ - glucosidase treatment), FA V2 (bentonite treatment), FA V3 (glutathione treatment), FA V4 (tannin treatment), FA V5 (gelatin and tannin treatment).

The fermentation process was conducted in glass vessels that were deposited in a room with controlled temperature $\left(18^{\circ} \mathrm{C}\right)$ for two weeks.
After alcoholic fermentation, the wines were filtered using a filtration-filling device (Tenco Enol-maticR; Avegno, Italy), followed by sulfur dioxide addition $(75 \mathrm{mg} / \mathrm{L})$ to preserve wine from microbiological damage. Bottling was done with a semi-automatic device.

Standard chemical analyses according to OIV methods: After decarbonation, each experimental sample was analyzed for: sulfur dioxide, volatile acidity, total acidity, alcoholic strength, density, total dry matter and nonreducing substances and $\mathrm{pH}$ according to the OIV Compendium of International Methods of Analysis of Wine and Musts.

The index of polyphenolic compounds: The index of polyphenolic compounds was determined by the spectroscopic method Folin- Ciocalteu using a Shimadzu UV-1800 spectrophotometer at $750 \mathrm{~nm}$.

Evaluation of chromatic characteristics: A Shimadzu UV-1800 spectrophotometer was used to determine the chromatic characteristics according to CIE Lab76 (OIV, 2013c).

Organoleptic evaluation of the experimental samples: Evaluation of aromatic profile of wines by "closed" tasting was made by the method proposed by the International Union of Oenologists and it is based on a considerable number of bonus points, corresponding to the organoleptic characteristics of wines.

This method aims to characterize wines in terms of specific flavor, smell and taste and the achievement of an aromatic profile. For this, it has chosen a number of 11 olfactory features and 8 taste features relevant, which can be found in the white wines analyzed.

Statistical analysis: A paired t-test was used to determine the differences between physicalchemical features of the control sample (V0) and each sample that was submitted to

a different treatment (V1, V2, V3, V4, V5). It is necessary to emphasis, that in this statistical analysis, they were considered the following features: volatile acidity, total acidity, relative density, alcohol concentration, reductive substances, T. D. E., N. E. and pH values.

\section{RESULTS AND DISCUSSION}

This article is a comparative study of some samples of Fetească albă wines produced in the year 2014, treated in pre-fermentative stage 
Tab.1. Physical-chemical analysis of wines

\begin{tabular}{|c|c|c|c|c|c|c|c|c|c|c|}
\hline \multirow[b]{2}{*}{$\begin{array}{c}\text { Wines } \\
\text { considered }\end{array}$} & \multicolumn{2}{|c|}{$\mathrm{SO}_{2} \mathrm{mg} / \mathrm{L}$} & \multirow{2}{*}{ 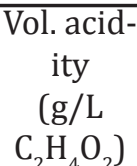 } & \multirow{2}{*}{$\begin{array}{c}\text { Total acid- } \\
\text { ity } \\
(\mathrm{g} / \mathrm{L} \\
\left.\mathrm{C}_{4} \mathrm{H}_{6} \mathrm{O}_{6}\right)\end{array}$} & \multirow[b]{2}{*}{$\begin{array}{l}\text { Relative } \\
\text { density }\end{array}$} & \multirow{2}{*}{$\begin{array}{c}\text { Alc. } \\
\text { conc. } \\
(\% \\
\text { vol. })\end{array}$} & \multirow[b]{2}{*}{$\begin{array}{l}\text { Reductive } \\
\text { subst. }(\mathrm{g} / \mathrm{L})\end{array}$} & \multirow[b]{2}{*}{$\begin{array}{l}\text { T.D.E } \\
\text { (g/L) }\end{array}$} & \multirow[b]{2}{*}{$\begin{array}{l}\text { N.E. } \\
\text { (g/L) }\end{array}$} & \multirow[b]{2}{*}{$\mathrm{pH}$} \\
\hline & Free & Total & & & & & & & & \\
\hline Fete: & 3.09 & 91.97 & 0.23 & 6.55 & $\overline{0.9}$ & 12.18 & 77 & 19.6 & 18.83 & 3.4 \\
\hline Fetească albă-V & 25.70 & 75.25 & 0.22 & 6.65 & 0.9915 & 11.85 & 0.82 & 19.35 & 18.21 & 3.34 \\
\hline Fetească albă- $V_{2}$ & 36,23 & 89,18 & 0,23 & 5,99 & 0,9910 & 12,11 & 0,68 & 18 & 17,32 & 3,28 \\
\hline Fetească albă- $V_{3}$ & 48.92 & 107.14 & 0.30 & 6.61 & 0.9918 & 11.78 & 0.89 & 19 & 18.11 & 3.31 \\
\hline Fetească albă- $V_{4}$ & 30.03 & 97.54 & 0.25 & 5.63 & 0.9925 & 12.2 & 1.49 & 21.6 & 20.11 & 3.38 \\
\hline Fetească albă- $V_{5}$ & 39.94 & 100.02 & 0.19 & 6.48 & 0.9914 & 11.87 & 0.92 & 18.3 & 17.38 & 3.22 \\
\hline
\end{tabular}

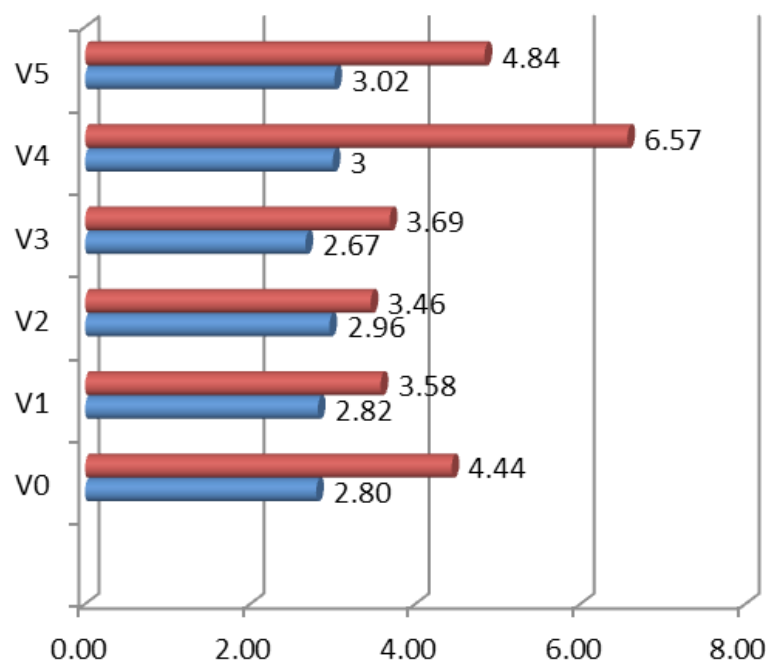

IFC (Folin-Ciocâlteu index)

D280 (total polyphenol index)

Fig.1. Total polyphenol index and Folin- Ciocâlteu index for the analyzed samples

with different oenological materials in order to emphasize their influence on the compositional level and not only.

The samples analysed were dry wines with over $11.7 \%$ vol. alc. In what concerns the samples treated with bentonite (V2) and tannin (V4), they were presenting lower acidity (under $6 \mathrm{~g} / \mathrm{L}$ tartaric acid) concerning the average of $6.3 \mathrm{~g} / \mathrm{L}$ tartaric acid. The volatile acidity has shown minimal values for all the samples, with an average of 0.23 $\mathrm{g} / \mathrm{L}$ acetic acid. A lower alcoholic concentration was shown by the samples: V1 (pectinase and $\beta$-glucosidase), V3 (glutathione), V6 (gelatin and tannin). Observing Tab.1, we can observe that the non-reductive extract has higher values (approx. $21 \mathrm{~g} / \mathrm{L}$ ) for the sample treated with tannin and that the $\mathrm{pH}$ values are typical ones, varying between a minimum of 3.22 and a maximum of 3.4 .

Using spectrophotometry it was observed the variation of two parameters, namely: the index of total polyphenols (IPT) and Folin- Ciocâlteu index (IFC) (Fig. 1).

The index of the total polyphenols recorded a maximum value of 3.02 for the sample treated with gelatin and tannin (V5) and a minimum value of 2.67 for the sample treated with glutathione (V3). In what concerns, the index of polyphenol with reducing proprieties, it had a higher value for sample V4 (tannin treatment) and a lower one for sample V2 (bentonite treatment).

By analyzing the data obtained, it can be observed that the majority of the samples, presented green and yellow shades of color, excepting sample V4 (tannin) where predominated red and yellow shades of color.

From the analysis of the $\mathrm{L}$ parameter (brightness) (Tab. 2), resulted that the samples presented a high level of clarity. With the increase in $\mathrm{C}$ parameter, changes occur in the color visually inspected, so sample V4, which has the highest 
Tab. 2. Chromatic parameters obtained for the analyzed samples

\begin{tabular}{ccccccc}
\hline $\begin{array}{c}\text { Analysed sam- } \\
\text { ples }\end{array}$ & \multicolumn{7}{c}{ CieLab76 } & Cromaticity & Crome C & Tonality (H) & Lighteness & Tempt \\
\cline { 2 - 7 } & 98.53 & $\begin{array}{r}-\mathrm{a}=0.203 \\
+\mathrm{b}=3.631\end{array}$ & 3.637 & -86.785 & 0.086 & 2.937 \\
\hline $\mathrm{V}_{0}$ & 98.82 & $\begin{array}{r}-\mathrm{a}=0.306 \\
+\mathrm{b}=3.571\end{array}$ & 2.521 & -86.352 & 0049 & 4.738 \\
\hline $\mathrm{V}_{1}$ & 99.62 & $\begin{array}{l}-\mathrm{a}=0.398 \\
+\mathrm{b}=2.361\end{array}$ & 2.394 & -80.427 & 0.041 & 6.683 \\
\hline $\mathrm{V}_{2}$ & 99.79 & $\begin{array}{l}-\mathrm{a}=0.338 \\
+\mathrm{b}=2.448\end{array}$ & 2.472 & -82.133 & 0.038 & 6.465 \\
\hline $\mathrm{V}_{3}$ & 98.76 & $\begin{array}{l}+\mathrm{a}=0.052 \\
+\mathrm{b}=4.445\end{array}$ & 4.445 & 89.329 & 0.085 & 3.466 \\
\hline $\mathrm{V}_{4}$ & 100.49 & $\begin{array}{l}-\mathrm{a}=0.511 \\
+\mathrm{b}=2.511\end{array}$ & 2.563 & -78.500 & 0.011 & -5.440 \\
\hline $\mathrm{V}_{5}$ & & & & & &
\end{tabular}

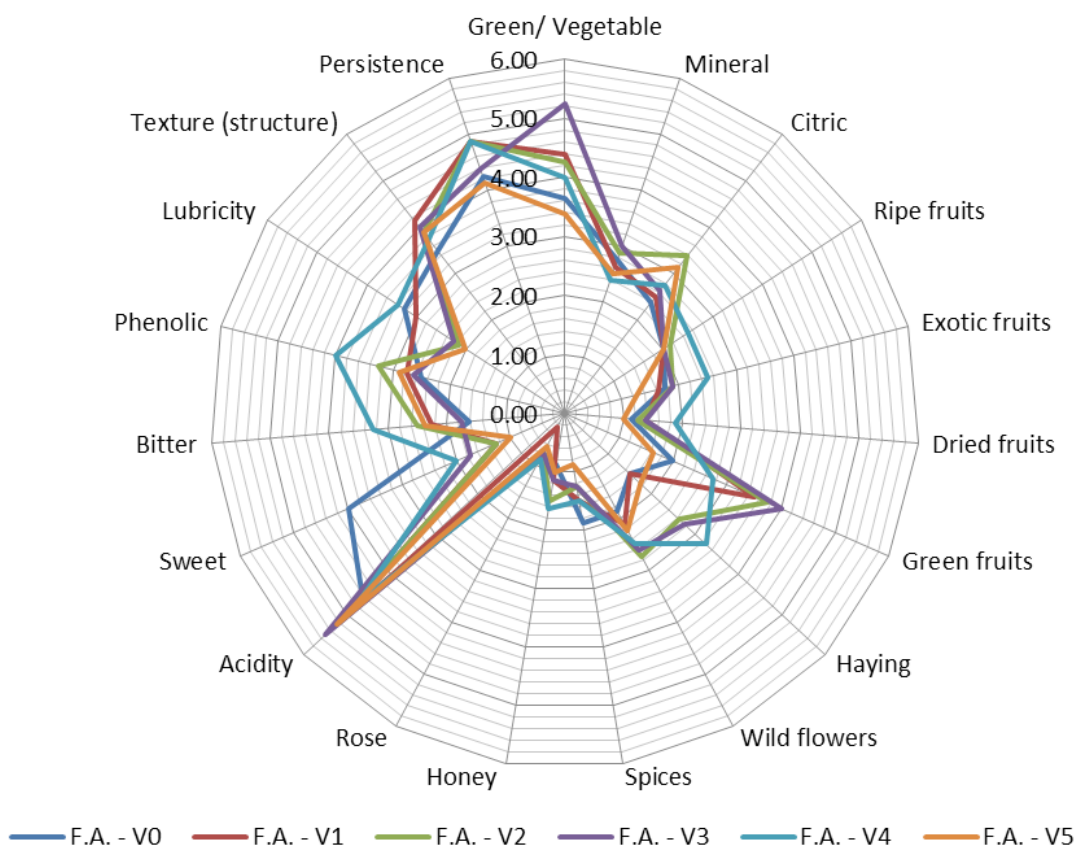

Fig.2. The chart of organoleptic features of the analyzed samples

saturation value (4.445), also had a more intense color.

Correlation between values of parameter $\mathrm{H}$ and colors perceived visually is part of the linear color space CIE-LCH. Tonality of color had negative values for the majority of the samples, excepting sample V4, where it was recorded a positive value.

The lightness parameter presented a lower value for sample treated with glutathione (V3) and similar values for the control sample and the sample treated with tannin (V4). It is important to highlight that the control sample and sample
V4 have shown the higher values for the lightness parameter.

The chart of organoleptic features presented above in Fig. 2, showed that all the wines have a high level of acidity that is specific for the wines obtained from Fetească albă grape variety.

Furthermore, it can observed that the sample treated with glutathione (V3) presents the highest level of acidity and expresses the higher level on green fruits and vegetable/ green flavors. The citric flavor is prevalent in the sample treated with bentonite (V2) and the haying and exotic fruits 
Tab. 3 Statistical analysis ( $\mathrm{t}$ - test) applied for the analyzed samples

\begin{tabular}{|c|c|c|c|c|c|c|c|c|c|c|}
\hline Group & \multirow{2}{*}{\multicolumn{2}{|c|}{$\begin{array}{l}\mathrm{V} 0: \mathrm{V} 1 \\
0.1480\end{array}$}} & \multicolumn{2}{|c|}{ V0: V2 } & \multicolumn{2}{|c|}{ V0: V3 } & \multicolumn{2}{|c|}{ V0: V4 } & \multicolumn{2}{|c|}{ V0: V5 } \\
\hline $\mathrm{P}$ (significance) & & & \multicolumn{2}{|c|}{0.0788} & \multicolumn{2}{|c|}{0.1393} & \multicolumn{2}{|c|}{0.2676} & \multicolumn{2}{|c|}{0.1096} \\
\hline $\mathrm{t}$ & \multicolumn{2}{|c|}{1.6259} & \multicolumn{2}{|c|}{2.0561} & \multicolumn{2}{|c|}{1.6677} & \multicolumn{2}{|c|}{1.2042} & \multicolumn{2}{|c|}{1.8320} \\
\hline Df & \multicolumn{2}{|c|}{7} & \multicolumn{2}{|c|}{7} & \multicolumn{2}{|c|}{7} & \multicolumn{2}{|c|}{7} & \multicolumn{2}{|c|}{7} \\
\hline $\begin{array}{l}\text { Standard error of } \\
\text { difference }\end{array}$ & \multicolumn{2}{|c|}{0.086} & \multicolumn{2}{|c|}{0.240} & \multicolumn{2}{|c|}{0.117} & \multicolumn{2}{|c|}{0.322} & \multicolumn{2}{|c|}{0.218} \\
\hline \multirow{2}{*}{ Mean } & V0 & V1 & V0 & V2 & V0 & V3 & V0 & V4 & V0 & V5 \\
\hline & 7.818 & 7.678 & 7.818 & 7.325 & 7.818 & 7.623 & 7.818 & 8.206 & 7.818 & 7.418 \\
\hline \multirow{2}{*}{ SD (standard deviation) } & V0 & V1 & V0 & V1 & V0 & V1 & V0 & V1 & V0 & V1 \\
\hline & 8.054 & 7.854 & 8.054 & 7.459 & 8.054 & 7.739 & 8.054 & 8.680 & 8.054 & 7.480 \\
\hline \multirow{2}{*}{$\begin{array}{c}\text { SEM (standard error of } \\
\text { the mean ) }\end{array}$} & V0 & V1 & V0 & V2 & V0 & V3 & V0 & V4 & V0 & V5 \\
\hline & 2.847 & 2.776 & 2.847 & 2.637 & 2.847 & 2.736 & 2.847 & 3.068 & 2.847 & 2.644 \\
\hline \multirow{2}{*}{$\mathrm{N}$ (number of subjects) } & V0 & V1 & V0 & V2 & V0 & V3 & V0 & V4 & V0 & V5 \\
\hline & 8 & 8 & 8 & 8 & 8 & 8 & 8 & 8 & 8 & 8 \\
\hline Mean $V_{a}$ - Mean $V_{b}$ & \multicolumn{2}{|c|}{0.140} & \multicolumn{2}{|c|}{0.493} & \multicolumn{2}{|c|}{0.194} & \multicolumn{2}{|c|}{-0.387} & \multicolumn{2}{|c|}{0.4} \\
\hline Confidence interval (\%) & \multicolumn{2}{|c|}{95} & \multicolumn{2}{|c|}{95} & \multicolumn{2}{|c|}{95} & & & & \\
\hline
\end{tabular}

flavors are better expressed in the sample treated with tannin (V4).

It can also be concluded that sample V4 (tannin) expresses the highest level on the phenolic and bitter taste. In addition, the sweet taste reaches a maximum level on the control sample and a minimum one on the V5 sample (gelatin and tannin).

In order to emphasis the impact of the treatments on the physical- chemical features of the analyzed samples it was conducted a paired t-test. The statistical test was applied on two groups: group A that is an invariably group represented by the control sample (V0) and group B that is a variably group that represents the samples that were submitted to different treatments (V1, V2, V3, V4, V5).

For each pair (V0:V1; V0:V2; V0:V3; V0:V4; $\mathrm{V} 0: \mathrm{V} 5$ ) it was considered a general hypothesis: that the treatments applied on samples V1 (pectinase and $\beta$ - glucosidase addition), V2 (bentonite addition), V3 (glutathione addition), V4 (tannin addition), V5 (gelatin and tannin addition) have a significant influence on the physico- chemical features of the analyzed wines.

Observing Tab. 3 it be observed that for each pair the value of $P$ (significance) is higher than 0.05 , so we can state that the considered treatments didn't have a significant impact on the physico- chemical features of the analyzed wines.

\section{CONCLUSIONS}

Following the results of the physicochemical characteristics (specifically the alcohol concentration) obtained by analyzing the considered samples we can include them in the category of quality white dry wines.

So, in this preliminary study, it can be concluded that the pre- fermentative treatments didn't had a major influence on the physicochemical features such as: alcohol, density, volatile acidity, total acidity, T. D. E., N.E., pH, etc, which it was demonstrated by statistical analysis.

The considered treatments had a significant influence on the phenolic profile and also on the aroma compounds, due to the differences found at sensory level.

\section{REFERENCES}

1. Harbertson JF, Parpinello GP, Heymann H, Downey MO (2011). Impact of exogenous tannin additions on wine chemistry and wine sensory character. Food Chem. 131: 999-1008.

2. Losada M, Andres J, Cacho J 2011. Influence of some pre- fermentative treatments on aroma composition and sensory evaluation of white Godello wines. Food Chem. 125: 884-891;

3. OIV (2013c): International oenological codex. - Paris: Organisation International de la Vigne et du Vin, 2013;

4. Parker M, Smith PA, Birse M, Francis IL, Kwiatkowski MJ, Lattey KA, Liebich B, Herderich MJ (2007). The effect of pre- and post-ferment additions of grape derived tannin on Shiraz wine sensory properties and phenolic composition. Australian J. Grape Wine Res. 13(1): 30-37;

5. Ribereau-Gayon P, Dubourdieu D, Doneche B, Lonvaud A (2006a). Handbook of enology. Vol. 1: The microbiology of wine and vinifications. $2^{\text {nd }}$ ed. - Chichester: Wiley, 2006;

6. Salinas MR, Garijo J, Pardo F, Zalacain A, Alonso GL (2003). Color, polyphenol, and aroma compounds in rosé wines after pre- fermentative maceration and enzymatic treatments. Am. J. Enol. Vitic. 54, 195-202. 